*Not for circulation * Author's proof copy * Submitted to New Media and Society*

\title{
Digital and networked by default? Women's organisations and the social imaginary of networked feminism
}

\author{
Aristea Fotopoulou \\ University of Sussex, UK
}

\begin{abstract}
This article analyses the social imaginary of "networked feminism" as an ideological construct of legitimate political engagement, drawing on ethnographic study conducted with London-based women's organisations. For many women's groups, the desire to connect echoes libertarian visions of Web 2.0 as an "open" and "shared" space, and it is encouraged by widely circulating governmental narratives of digital inclusion. In the context of public services becoming digital by default, and severe funding cuts to volunteer organisations in the UK, feminist organisations are invited to revise the allocation of resources, in order to best accommodate the setting up of digital platforms, and at the same time, to maintain their political and social aims. It is argued that there are tensions between the imaginaries of a "digital sisterhood" and the material realities of women's organisations: age, lack of resources and media literacy were found to be the three most important factors that modulate participation, and in many cases become new types of exclusions of access to publicity and recognition. By interrogating the circulation of dominant liberal narratives of digital engagement and digital inclusion that motivate new communicative practices between many feminist organisations today, the article offers a fuller understanding of networked media and activism for social justice.
\end{abstract}




\section{Keywords}

Social imaginary, networked feminism, digital sisterhood, connectivity, political engagement.

Corresponding author: Aristea Fotopoulou, School of Media, Film and Music, University of Sussex, Falmer Brighton, BN1 9RG, UK. Email: a.fotopoulou@sussex.ac.uk 


\section{Digital and networked by default? Women's organisations and the social imaginary of networked feminism}

Openness, then, constitutes the conditions that give rise to the most general of the political concerns expressed by a network culture (Terranova 2004, 62).

\section{Introduction}

Is feminism becoming networked and are we moving into an era of "digital sisterhood"? This article investigates understandings, hopes and fears relating to networked connectivity, drawing on ethnography with feminist organisations based in London. The empirical material is collected through interviews with organisations and individuals who are members of a wide and diverse UK feminist network, which is inspired by the Women's Liberation Movement. The analysis focuses on the values, languages and ideologies that shape practices of networked connectivity for these groups, and which make up a shared "social imaginary" (Taylor 2002) of legitimate political engagement. Research findings suggest that, for women's groups today, the desire to connect echoes the libertarian promises of Web 2.0 as an "open" and "shared" space. Participants recognised that processes of computerisation are widespread, and that some form of digital engagement was necessary: first, they have to compete with established structures of institutional power - for instance, by responding to governmental consultations, where agenda issues are already defined by powerful actors; second, they have to compete for political voice, recognition and publicity in online spaces where other social actors campaign. They were thus concerned about their role and their capacity as situated political subjects, when the default mode of campaigning and communication for activists seemed to have become digital and networked. Of course, feminist politics are a moving target and it is difficult to capture how they evolve whilst technologies are 
also changing. At the same time, there are differences between groups with a long history (such as the Fawcett Society group ${ }^{\mathrm{i}}$ ) and organisations who have emerged after Web 2.0, not only politically, but also in their understandings of technology. What is more, in the UK the language of feminist waves has less hold among feminists than in the US, and it is the re-invigoration of the principles and histories of the Women's Liberation Movement that characterises contemporary British feminism. These differences (between generations of activists, technological literacies, and political agendas) are acknowledged in the article; however, it is important to identify commonalities among feminists in their motivations for new communicative practices, in order to more fully understand the relationship between networked media and activism for social change.

The context of this research is a climate of widespread economic crisis in the $\mathrm{UK}^{\mathrm{ii}}$, which led to funding cuts for most grassroots feminist groups ${ }^{\text {iii }}$, including refuges for trafficked women, such as Eaves4Women (Townsend, 2011), and Rape Crisis provisions across the capital (North London Fawcett Group, 2009). During the period of the study, the final Parliamentary Readings of the Policing and Crime Bill 2009 (now an Act) were taking place. Therefore the issues prominent in the agendas of most activist groups analysed here largely concurred with the reforms proposed in the Bill $^{\text {iv }}$. For example, the theme of the Feminism in London conference was: "Pornification, the pay gap, eating disorders... Where do we go from here?". At the same time, changes in the digital communications landscape, shaped to a large extent by the Digital Economy Act and Ofcom, are paving the way for public services (e.g. eLearning, eGovernment, eHealth) to become "digital by default" (Helsper 2011). In this context of digital, and I would like to add, networked, by default, feminist organisations find themselves rethinking their allocation of resources, in order to best accommodate the setting up of digital platforms and networks, and at the same time, to maintain their political and social aims of supporting women.

Digital networks in Web 2.0, with its social and mobile media applications (such as wikis, 
social networking platforms such as Facebook, weblogs and microblogs such as Twitter, video and photo sharing sites like YouTube), are becoming a space of civil society. Web 2.0 is often thought to be inherently social and participatory, and distinct from Web 1.0. It also has made the internet accessible to mobile phone users who cannot afford a personal computer. Digital networks are not only efficient when it comes to sharing information; online, public concerns can be framed in unique ways, as actors come together in real time to "make things public" (Latour and Wiebel, 2005) and to claim voice and recognition (Couldry, 2010).

However, although network technologies offer the possibility for high speed, far-reaching campaigning, and connecting across space and time, setting up digital infrastructures within organisations may also be detrimental for those women's groups that are under-resourced due to public spending cuts. This is because it draws them towards prioritising processes of on-going change, training and innovation within organisations, at the expense of other, more sustained forms of engagement. The implementation of - frequently drastic - changes within feminist organisations that accommodate digital communications and technological innovation needs to be considered in relation to what has been framed as the "cultural logic of computation" (Golumbia, 2009) and elsewhere, "the regime of computation" (Hayles 2005). In this article, the focus is on the circulation of certain discourses, values and ideologies; whereby gender-related political activity is linked to the widespread use of network technology and ubiquitous computation, and that contribute to the social imaginary of networked feminism. These are, namely, dominant framings of digital engagement and digital inclusion; dominant framings of the digital way of life as a productive and progressive "good life"; cyberfeminism; and utopian cyber-libertarian narratives. This is not to say that digital infrastructure and training are not important for feminist third sector organisations; instead, as it is argued in this article, we should approach the complexity of digital media for activists through grounding our inquiry in the values and practices of feminists, and in the situated 
conditions in which social actors operate, if we are to avoid recreating grand narratives of unified digital presence, and the exclusionary implications of such narratives.

\section{a) Digital engagement, cyberfeminism and computational narratives}

Digital engagement is often used to describe the adoption of a set of digital media practices (social media, email, websites) by both civil society organisations and individuals from marginalised groups that are also usually targeted by governmental agencies. Framed as "any use of social media by a corporate organisation, right through to more specific definitions around how public sector organisations promote participation in policymaking” (The Digital Engagement Guide, 2013), it often takes merely the form of consultations in existing governmental websites and platforms (See Government Digital Service, 2013). Instead of digital engagement, governmental rhetoric shows preference for the term digital inclusion. For instance, having identified that 150 million Europeans (30\%) have never used the internet, the 2010 European-wide directive Digital Agenda for Europe has proposed interventions that relate mainly to web access for socially disadvantaged groups (age group 65-74, low income, unemployed, less educated, people with disabilities) and minors; and to overcoming barriers to this participation ${ }^{\mathrm{v}}$. If we accept these narratives to be the dominant framings of a "digital way of life" and a "good life", we might want to question how such re-iterations of liberal rhetoric - whereby the internet is seen as an opportunity for economic growth, both for the country and the individual (Mossberger et al, 2008) - are compatible with and conductive of activist aspirations for social justice and gender equality. Outside these framings, it is well established that online media increasingly form part of the communication of social movements and civil society politics (Atton, 2002; Dalhgren, 2009; Lovink, 2002; Papacharissi, 2002). Civic engagement and political participation, facilitated by the use of digital technologies, today is a democratic aspiration (Bruns 2008, Schafer 2011). Feminists use networked 
media in order to stay connected and to engage new participants in their actions, and as Catherine Redfern and Kristin Aune (2010) recount in Reclaiming the F-Word, this means that new forms of feminism among younger women are emerging.

This dominant, liberal framing in EU and UK government sites is complemented by a wider circulation of social imaginaries, which is specifically relevant to feminist actors. "Social imaginaries" refer to the ways in which people imagine their social existence, social surroundings and their connections with others (Taylor, 2002). They are carried in images, stories and legends, and are significant precisely because they "make possible common practices and a widely shared sense of legitimacy" (Taylor, 2002, p.106). In the era of technoscientific globally networked societies, people imagine their social existence through both discursive and technical practices (Ketly 2005, 186), and it is through such practices, including the conditions of online access and web-linking behaviour, that feminist groups share a sense of legitimacy with other civil society actors.

Social and cultural imaginaries of technology and women have long been strong drives for visions and promises of a "networked feminism". Figurations of "cyberfeminism", itself a contested notion and a self-reflexive movement, which have circulated since the 1990s (Paasonen, 2011), play an important role in the performative articulation of this promise. As an art practice, the Australians VNS Matrix coined the term in 1991, claiming a feminine corporeality of technology with irony and subversion. Donna Haraway's (1991) cyborg metaphor, Sadie Plant's (1997) account of machines and women and Sandy Stone's (1995) “online fluidity", have all inspired how the internet has been imagined by feminist users during the last twenty years. These often techno-utopian visions of technology and women can be thought to occupy space alongside other more widespread imaginaries of the internet as an open space and web 2.0 as a participatory, and hence distinctly empowering ecology for the individual user. US futurist technology "gurus", intellectuals, 
entrepreneurs and media reportage have long generated "cyber-libertarian 2.0" discourses (Dahlberg, 2010, p.334) and ICTs and "web 2.0" models operate widely in such imaginary modes (Bassett, 2008). Google has built its whole marketing strategy on such a liberal imaginary of neutrality and not-for-profit publicness (van Dijck, 2013). The ideological underpinnings of these imaginaries make it necessary to analyse in relation to contemporary feminist activists, as they are indeed driven by both visions of connectivity and by visions of a feminist movement. Such computational visions of social change, in other words visions of social change and sisterhood in which networked connectivity and ICTs are central, shape to a large extent the priorities of feminist activists. As it is suggested in the empirical analysis of this paper, these imaginaries are at the same time indications of a feminism with a distinct identity in networked environments, and symptoms of a prescribed and controlled mode of digital and networked engagement. At the same time, digital and networked practices become a key feature of these organisations, their sense of who belongs in feminism as a social movement, and who is excluded from the identity "feminist", which is often performed online.

\section{b) Research context and methodology}

The reflections presented here have emerged out of fieldwork with a variety of women's organisations, which are mainly volunteer-run and receive limited or no state funding. They occupy different positions in the political spectrum and have different campaign priorities: antipornography (Object, LFN); anti-trafficking (e.g. Eaves for Women); poverty and equal pay (Fawcett); rights of minority groups and asylum seekers (e.g. South Bank sisters). Here, I draw on personal and public accounts recorded during in depth semi-structured interviews with twelve activists, and during participant observation at various events organised by women's organisations, including the Feminism in London 2009 annual Conference, the Women's Resource Centre 2010 
Annual General Meeting, and the 2010 “Women's Liberation Conference@40” at Ruskin College in Oxford. I interviewed participants in the Feminism in London Conference, an event of increasing centrality in British grassroots feminism, organised annually by the London Feminist Network (a women-only feminist networking and campaigning organisation established in 2004 that organises the annual Reclaim the Night event). Participating groups were Object, a human rights organisation that challenges the sexual objectification of women through "lads' mags", lap dancing clubs or sexist advertising; the Fawcett Society, a leading UK-charity campaigning about pensions, equal pay, poverty and social justice; the London Feminist Network; and the Women's Resource Centre, a national umbrella organisation for women's charities, with over 500 members. I also interviewed journalist and Green Party candidate at the time Beatrix Campbell and psychoanalyst Susie Orbach. This sample is by no means representative ${ }^{\mathrm{vi}}$; it captures, however, the heterogeneity of feminist actors and the different understandings of what feminist politics in digital networked environments mean today ${ }^{\mathrm{vii}}$.

\section{Versions of contemporary feminism and network imaginaries: changing} organisational practices and making meaning of digital media

\section{a) "A building with women through its veins"}

Most feminist activists who were interviewed for this study found Web 2.0 tools to be essential to their identity as active participants in a historically long-standing feminist movement. Being active in online social networks in particular, by generating and circulating content, gave them a sense of connectedness with other feminists across space and time. Jose van Dijk (2013) has written about a wider shift in the behaviours of internet users, from practices of connectedness to practices of connectivity. Although for London women's groups there was clear orientation towards 
practices of connectivity, these practices did not replace the offline habits, such as informal meetings and conferences, that brought them together on an everyday basis. Nevertheless, participants to a large extent understood digital media and networks as technologies and spaces that enable intergenerational and "translocal" (Hepp, 2008) connections between feminists. This was of big value to them, and as a result, influenced their decisions about setting up new social media platforms, the degree to which they mobilised through them, and the form that this engagement took with and beyond social media.

One of the key actors in this network who prioritised the development of digital infrastructures was the Women's Resource Centre (WRC). The WRC perceived social media as a new space for activism and promoted the idea that online networking among women's organisations is necessary for its affiliated members. It set up an online social networking platform called The Café, which in its two month pilot phase involved 150 women's organisations. A survey the WRC conducted about how women's organisations use the internet found that $25 \%$ did not have their own website. The WRC understood this to indicate technophobia amongst women's organisations. A sustained effort to overcome the scepticism among women's organisations towards social media platforms was made by Sandra, the Centre's communications officer, who provided this training, including a printed step-by-step guide for using the Café.

. She noted: "I've been talking about social media a lot, you know, so kind of introducing them to the idea of using things like, using Twitter, Facebook, things like that".

Twitter had been significant for the WRC in many ways: it was used to locate funding opportunities, to learn about policy consultations, to set up new memberships and to share relevant information with their members. Sandra's enthusiastic account of Twitter corresponds with a widespread perception of network media as transparent modes of communication. Echoing open 
architecture aspects of digital networks, alongside discourses of interactivity and participation, the WRC spokesperson stressed that online communication media facilitate horizontal ways of connecting ${ }^{\text {viii }}$. Sandra used the metaphor of open architecture to explain how localised, individual and relatively small feminist organisations can now connect in a common conversation, using a common language: "It is a bit like opening the roof of an organisation. People can dip in and out".

Interestingly, in the same event, the building metaphor was used by the Chief Executive of the Centre, when in her speech she described their offline action plans. She envisioned a building in London that would host women's voluntary organisations, "a building with women through its veins" (WRC AGM 2009). This latter vision of openness and collaboration then corresponds to a concrete version of the digital media open-roof organisation. Although the building was physically placed in the centre of London, whereas the Café was virtually anywhere, both maintained the WRC as the central node of their connection. Keeping the Women's Resource Centre as the central node was essential, because the WRC maintained links to funding sources and to policy makers, which individual local charities often lacked. In this sense, the online platform not only brought charities in contact with one another, but additionally gave them a communication venue through which their concerns could reach officials.

The wider rhetoric of digital networks as sites of non-hierarchical modes of connection (Terranova 2004) and as elementary components of democratic participation (Bree 2002, Downey 2008) underpinned the narrations of all participants. Networked feminism in this vision was a decentralised structure, which allowed women's groups to connect in an optimum way; it is ubiquitous and inclusive. Being part of "the network" for many interviewees implied belonging in a wider timeless movement. For example, when Finn Mackay (2009), the spokesperson of the London Feminist Network, described the action of the London Feminist Network and feminism 
more broadly in an email interview, she thought of it as a continuation of the Women's Liberation Movement. However, the LFN's vision of a unified political movement in an open digital space often came into direct conflict with the exclusionary practices that these feminists performed offline, on the ground: the LFN excluded trans women from its spaces, and in some cases, Reclaim the Night marches reinforced the exclusion of sex workers from feminism. At the same time, rather than perceiving their position in a feminist network as a local or micro-struggle in a horizontal assemblage, as for instance a "multitude" (Hardt and Negri 2004) reading would have it, participants imagined the centre to be a physical place, London. Such exclusions (of marginalised groups and localities) are indicative of how social imaginaries of networked media as the facilitators of unified feminist identity are often problematic when it is at odds with the material reality of what feminisms are permitted and demonstrated.

\section{b) Catching up with technologies and changing organisational routines}

Whilst the imaginary of instant high speed transnational communication among feminists stimulated digital engagement for many of the groups, there was also a lot of anxiety about catching up with technologies. Participants talked about their sense of a knowledge gap - a digital literacy gap - which was widening. Ellen Helsper (2011, p.2) has argued that a "digital underclass" is forming in Britain, and that "as the government plans to make public services 'digital by default' these individuals will be unable to access them, not because of a lack of infrastructure but because of a lack of (effective) take up of the available connections". Indeed, older feminist activists who were part of Women's Lib were particularly worried about isolation due to lack of connectivity, especially since they already felt that a generational gap distanced them from current developments and younger activists. For example, Beatrix Campbell, responding as an individual, rather than as part of an organisation, explained how for her new media literacy was a requirement for meeting up 
with the demands of digital audiences, and particularly of those who follow her journalistic and political activity. She explained how learning to use social media was also a personally transformative experience:

I know that that's generational, and I know that that's not useful....so it's kind of ambivalent, slightly technophobic, slightly utilitarian approach to new means of communication.

She went on to remark:

$[R]$ egularly, I realise I can't intervene, I didn't know my way around the kind of debates...so I do my thing and that's it.[...] I have to become technically literate [...] I'm just going to change.

Media training seemed for many activists to be a key condition for acquiring representational space online. Participants used a language that expressed urgency, necessity - not merely opportunity.

Although most groups and activists see the necessity of having a web presence, some understand their role to stimulate dialogue and mobilisation to be more important than expressing the interests of a specific group. This diversity of such understandings is important, because as noted next, feminist engagement and communicative activity in digital networks is not just a matter of transmitting information, or exercising rational exchange in a new space; it also relates to a fear of being left out and of being forgotten. In the next section I discuss the implications of media literacy and access to Web 2.0 digital culture for older feminists and their sense of being excluded and historically erased. 


\section{c) "That's our own Facebook, we meet face-to-face": New media literacy and offline}

\section{networking}

Seeking to address new media literacy, the South London Fawcett Group (SLFG) and others invested time and effort in making digital media part of their organisation. Clearly, for those who worked at the WRC (younger and already familiar with Web 2.0 technologies) joining the new Café platform demanded little extra effort; they already had an everyday pattern of use of mobile media technologies and were tweeting from the FiL09 conference. However, for older women of the South London Fawcett Group (SLFG), becoming members of a new platform took considerable effort; they already struggled to incorporate email technology in their organisational mode of operation. The fact that as affiliated members, SLFG received training from the Women's Resource Centre, didn't make much difference.

Implementing a social online networking platform, for example the Café or even Facebook, required as much work as domesticating Web 1.0 tools (email technology and email lists) for the SLFG. This is important because it shows that older women who lack digital skills and basic access cannot differentiate between web 1.0 or web 2.0 and therefore cannot benefit from the additional layers of connectivity, and subsequently political engagement, that are possible. As the following quote, from my interview with SLFG on the $30^{\text {th }}$ of October 2009 , shows, the channels through which they can reach the government, policy makers or mainstream media remain more or less the same:

We have talked about having Facebook group, we don't have a Facebook group [...] but again to the older members it's a novelty, which we have to get accustomed to. In a way, we meet once per month, we have good discussions, that is sufficient. That's our own Facebook, 
we meet face-to-face.

This understanding is very different to the vision expressed by the WRC; what the WRC described as "dipping in and out of organisations", with the use of social media, seemed highly complicated and even utopian considering the reality of digital engagement for older women. Nonetheless, the SLFG had a fascinating story to narrate about the parallel evolution of their group and its digital capacity:

[The SLFG] has developed with the evolution of digital communications. [...] It happened so fast...And it is, quite a difference of experience between older members and younger members [...] But on the whole we try to keep up, we can't, we can't, if we didn't people would not be interested in us (SLFG, 2009) (my emphasis).

In this narration, digital engagement and new networking communication technologies are not exciting opportunities - they are a one-way street. Participants felt they ought to be producing digital texts, or else the world will pass them by. Combined with the narration of the ease with which younger activists adopt social media and digital technologies more generally, a key concern is expressed here: primarily, there is a fear of exclusion from political life and social life more generally, of older feminists and their histories. The implications of this concern are important because they relate to the legitimacy of new communication technologies when they become the measure for political engagement.

\section{Discussion.}

a) "Digital sisterhood", material constrains and the struggle for legitimacy 
As it emerges from this fieldwork, the changing attitudes to and practices of political engagement for various activist groups are influenced by a dynamic set of feelings and experiences: enthusiasm, uncertainty and fear. The enthusiasm about participation, openness and connectivity ensues from the dominant understandings of connectivity that circulate today and which constitute, following notions of social imaginary (Ketly, Mansell, Taylor, Van Dijck), the "network imaginary" for feminists today. Enthusiasm about the potential of creative and shared production for feminist activism is complemented by uncertainty about the conditions of heterogeneity and decentralisation. David Morley (2001) and Arjun Appadurai (1995) have early on talked about the destabilising effects of globalization and about how the sense of place and neighbourhood shifts with network communications. Here, the distinct sense of finding one's place and belonging in feminism and digital environments is historically re-worked in the notion of "sisterhood": although criticised (hooks, 1986), the notion of "sisterhood" - initially suggested by Robin Morgan (1970) - can still be thought to accommodate what Deborah Rosenfelt and Judith Stacey wrote is the need to "develop cultural forms that fill some of the [...] longings for intimacy, interdependency, and emotional security" (1987, p. 46) for feminists. Digital networks contribute to the building of such cultural forms, of what could be termed as "digital sisterhood", where feminist groups and women turn for support. However, as has been noted, this sisterhood as neighbourhood is located at the intersections of online spaces with the everyday off-line physical interactions, and creates its own exclusions.

The tension between insecurity and intention to participate in digital networks for the development of a "digital sisterhood" is of course experienced by feminist activists today not as individuals, but as collectivities who claim a legitimate political voice, in a fast-paced technologically advanced world. At a time and space where ephemeral media and digital connections, for instance the Arab spring seem to be valued more (Curran, Fenton and Freedman, 2011) than the lived histories of political movements, the challenge for these actors is how to 
validate their off-line tactics, campaigns and demonstrations on the street.

This struggle for meaning and legitimacy is ever so important for these feminist groups because they have to compete for voice (Couldry, 2010) in the public sphere from a position of limited or absent funding, and as is evidenced below, low digital literacy. One example of limited resources is that the organisation Anybody did not have a volunteer role exclusively for website moderation, which in turn affected the amount of interaction with the people using the website. Susie Orbach, speaking to me as the organisation's spokesperson, stressed: "It's all informal and voluntary. So you might get a twenty-year-old, who comes and says she's going to set a zine up, she's going to do this, but then it doesn't deliver necessarily" (2009). While maintaining a multiple web presence was challenging for organisations that did not change their mode of operation on a wider scale, for the London Feminist Network the email list was their constitutive activity. It was created through two previous and now discontinued online mailing lists, the UK Feminist Action and the London $3^{\text {rd }}$ Wave. With approximately 600 members on their list at the time of the study, they mainly focused on disseminating information from the Women In London calendar of events. Thus although many groups did not have a communicative strategy guiding how, when or why they would adopt digital networking, they strived to get connected, because they understood this as a key aspect of maintaining activist engagement.

Of course others like Object! demonstrated a succinct communicative strategy, which was also indicative of their role as mediators between grassroots activists and the government; the website in the case of Object! was primarily a collection of resources, such as template letters to send to MPs. Object! additionally maintained a Yahoo! Group and a blog, which targeted activists. Part of their activist support was to supply evidence for community groups to use in court hearings or in council targeted motions against lap-dancing clubs opening in their area. Apart from acting as mediators between the government and activists, Object! as an organisation aimed at attracting 
mainstream media attention to their campaigns. Having the mainstream media report on these campaigns is arguably an important means of reaching out to wider audiences, and potentially brings debates to the public sphere. However Object! did not entirely rely on social networks and provocative media campaigning to get their message across; their communicative and organisational activity is rather complex, and indeed one could even say dispersed and networked: it lends activist support to Eaves and Fawcett, who are organisations with similar social power; it participates in a knowledge exchange and coordinates grassroots feminist groups who are starting up from zero level activity. It aimed to "share skills and build unity within the women's movement" (Object, 2009); and thirdly, the organisation functions as a communicative channel between feminist groups and mainstream media, for the expression of common concerns. Therefore if we were to name networked feminism as a form of contemporary political action that is characterised by complex connectivity and which operates at the intersections of online and offline, and across campaigning activities, feelings and people, Object! would be exemplary.

Although one could analyse specific feminist discussions on Twitter, my point here is that the intersection between online and offline is significant because it helps us question the bias towards online and always-connected forms of activism. This is a cultural bias that puts weight on the social media or otherwise visible-on-the-screen networks, and is a symptom of a wider "culture of connectivity" (van Dijck, 2013) in contemporary informational societies. In the next section I elaborate this point by questioning the notion of "networked feminism" as well as its currency in contemporary feminism, and by noting the tensions between the reality of new forms of exclusion and the promissory narratives of web 2.0 participation.

\section{b) Questioning networked by default: Social imaginary, ideology and digital culture}

Digital platforms, architectures, economies, in other words digital infrastructures, are 
becoming the default context where not only politics, but life in general takes place. Of course the potential of internet technologies to liberate the world has been seriously disputed in media studies, and it has even been called a "net delusion" in relation to social media and the Arab Spring (Morozov, 2011). Women's groups in this study have certainly not been delusional about the internet's potential for gender equality; however, my exploration evidenced that activists' attitudes were shaped by certain social imaginaries of networked politics, of participatory action and connectivity. These attitudes ranged from celebratory adoption of digital communication, to resistance to social media platforms. As mentioned, some groups set up websites and email lists; some were passionate about Twitter; and others introduced social networking platforms and prioritised new media training. Despite the differences in the micro-practices of organising and communicating between feminist participants, they shared values and languages of network participation, and the promise of networked feminism, but also the fear of being left behind and being left out.

The feminist groups and activists that I interviewed for this study were not obsessed with updating their profiles and online visibility, a Web 2.0 characteristic -.although their everyday interactions entailed sending emails and newsletters, this is a mainly Web 1.0 activity. Nonetheless, some form of digital engagement seemed to be understood as the condition for having political voice in the dissonance of neoliberal politics, which reminds us "why voice matters" (Couldry, 2010). The adoption of new communication technologies and social networking within civic organisations was also an indicator of 'keeping up' and progress. This understanding of participation and empowerment is problematically fused with productivity, administrative control and functionality, which are themselves ideological tools. There is a delicate difference however, between the social imaginary of networked feminism as a productive desire to keep up with technologies, and the understanding of digital engagement as the necessary and default condition 
for legitimate political voice. This difference needs to be noted in relation to current framings of interactivity, democracy and even activism as fantasies of "communicative capitalism" (Dean, 2009), where social actors are swayed by the desire to produce digital content. Jodi Dean suggests that contemporary communicative environments are shaped by technological fetishism, which manifests in neoliberal fantasies of active and participatory citizenship (Dean, 2009). Although it is politically important to recognise, and continually re-iterate, that neoliberalism is a global system which suffocates equality, thus far my examination of feminist groups' imaginaries relates less to abundance of mobile and web content. I agree that the circulation of computational discourses and internet imaginaries normalises computationalisation (Golumbia, 2009), reinforces wider power relations and reproduce dominant ideologies (Mansell, 2012). Indeed it is unclear how demands for recognition, such as gender and sexuality, which drive social struggles (Fraser and Honneth, 2003), fit with framings of distributed power and democratic participation in web 2.0, or how dominant framings of digital inclusion respond to activist aims. Here however, it is not my concern to draw a bleak picture of how computationalism and network technology failed to materialise the promise to deliver radical change in the global social and political fabric. Media studies is prolific in its ideological critique of computation (Berry, 2011; Chun, 2011; Fuchs, 2011). I would rather like to argue that the social imaginary of digital and networked participation, which is complemented by the computational logic, has a dark side: exclusion from what appears as the era of unhindered citizen participation. In particular, women's groups in this study, like other contemporary civil society actors, participate in the online public sphere (Downing, 2001; Gordon, 2007) in different degree; age, lack of resources and media literacy being the three most important factors that modulate this participation, and in some cases become new types of exclusions of access to publicity and recognition. Being neither hackers nor artists, these activists could not really work "through protocol" (Galloway, 2004) to achieve recognition. They lacked the necessary skills and 
resources that would allow them to resist the ubiquity of protocol. I noted how Beatrix Campbell was initially skeptical, alas eventually espoused Twitter and blogging, as a means for providing audiences with more choice. The Southern London Fawcett Group (SLFG), who were mostly older women, met face-to-face and humorously commented that this was their Facebook - but at the same time feared that they were "no longer interesting to the world", as they put it. Although the issues relating to new forms of exclusion and the impact of internet technologies on everyday life have been analysed in earlier work (Miller and Slater 2000), Web 2.0 creates a distinct media environment for connectivity, because of its always-on and social networking characteristics. Therefore the exclusions created are not plainly a matter of access and being online or offline, as was the case in the beginning of the 2000s; exclusions are more sophisticated and concern the frequency of updating online presence and producing more interesting content in social media. To reiterate, the notion of default in relation to digital and networked technologies is ideological because it refers not to how feminists could be producing an abundance of communicational texts and online content (social online platforms, newsletters, or creative code), but that they ought to be producing them, or else the world will pass them by. The tension between ought to and could participate and be empowered can be thought as symptomatic of the promises of "good life" and the "digital way of life". Sara Ahmed (2010) writes about the promise of good life, happiness and the good intentions behind it. The performative aspects of the promise order a future and make this future predictable, something to aim for. This promise and social imaginary of networked feminism, the online performance of a feminist identity, is a set of practices and discourses which shape social and cultural expectations about how life with digital media should be: digital media require our participation, our willingness to provide data for advertisers or for our own benefit. Participation and interactivity are becoming standard framings and the production of networked connections is central in the promise of empowerment. What makes the digital potentially political is the 
determination of people to connect, and to embody, in their communication practices, new forms of solidarity. The ethnographic study with women's groups was indeed positioned within this performative promise, with an underlying attitude that they ought to become digital and networked by default.

The default aspect of interactive technologies signals the "participatory web 2.0 as ideology" (Fuchs, 2011, p.257), and raises questions about the agency of social actors to position themselves in relation to it, and to shape their lives and political identity. The sense that activists ought to participate, and that networks are nowadays the norm, constitutes digital networks as a ubiquitus system and creates space for negotiation and opposition. Indeed, activists exercised their agency and often resisted the interactivity, open sharing practices and reconfiguration that the model of "digital and networked by default" represents. So far, when thinking about resistance in digital culture scholars have focused on forms of multi-actor ambivalence or resistance that relate to surveillance, face recognition and data harvesting, such as the United Kingdom National Identity Scheme (Martin et al., 2009). Other expressions of resistance to new media, which mainly respond to the assumed negative impact of digital technologies on the quality of family life and the development of youth, is by civic groups such as Slow Media (for digital disenchantment) or the National Day of Unplugging (http://nationaldayofunplugging.com/). If we think of everyday life and digital engagement as a form of free labor (Terranova, 2013; Andrejevic, 2011), nonconsumption automatically constitutes actors as non-producers (Portwood-Stacer 2012). As Laura Portwood-Stacer argues, refusing to participate in social media, quitting Facebook, or never joining it in the first place, is the object of resistance struggles, as well as a site for the representation of those struggles over meaning and resistance. Although, in the case of older feminists of the Southern London Fawcett Group, the refusal articulated by “this is our Facebook" is not necessarily an act of everyday resistance of the magnitude of a consumer strike (Cohen, 2003; de Certeau, 
1984; Micheletti, 2003), it exemplifies how activists define the permeability of physical social spaces by online media. By becoming what Ahmed (2010) would call “unwilling subjects", London feminists resisted, or just negotiated, not only their digital identity but also their political identity and their place in what appears to be a dominant digital culture which regulates how activists should connect nowadays. When they say "we meet face to face, this is our Facebook", the women of SFWG acknowledge that Facebook is the dominant form of connecting and additionally marks the new space for doing politics. This acknowledgement but unwillingness to participate (to be part, to be regulated) re-instates that feminist politics, although in dialogue with the digital, are not subsumed in the digital. As the previous discussion about the cultural forms of a "digital sisterhood" has shown, contemporary activists produce their own spaces and conditions for doing politics, even as the dominant culture of computationalism and networked by default seems to offer one universal set of practices for all political subjects. The agency of social actors who, in their own right, delineate how social media can be useful for their political aims, and how the "digital and networked by default" is something to be afraid of, or opposed to, cannot be questioned here. We may however want to problematise what it means for social agency more generally when political actors are legitimate only when operating with reference to a default context and their sole means of resistance are to "opt-out".

\section{Conclusion}

Imaginaries of computational ubiquity and user empowerment in web 2.0; fears of being historically and politically erased; and everyday resistances form the complex picture presented in this article, as a step towards a fuller understanding of the communicative practices among a diverse group of London-based women's organisations. Reading digital networks solely as public sphere (Downing, 2001), as spaces of activist opportunity (Galloway, 2004), spaces of web content abundance (Dean, 2009) or "digital enclosure" (Andrejevic, 2007), limits how feminist politics can 
be understood. The current analysis offers clear indications that, in the shared space of increased visibility and connectivity, feminists experience new forms of exclusion of access to publicity and recognition, as digital networks can be, at the same time, spaces of uncertainty and empowerment, depending on skills, resources and age. The social imaginary of "networked feminism" as an ideological construct of legitimate political engagement in the "open" and "shared" space of Web 2.0 technologies is cultivated by widely circulating narratives, including those of digital inclusion; and encouraged by the reality of public services becoming digital by default in the UK. However, the fact that ageing and media literacy were sticking points in the ways in which activists perceived themselves as political subjects in highly mediated environments opens up wider questions about the viability, or even necessity, of a feminism which is digital and networked by default. Historically feminist politics have been a politics of connectivity and affect; they have developed through networks, connections and relationships, which have produced knowledge and lived experiences (Jollie and Roseneil, 2012). We should thus keep rethinking the possibilities offered for social change by the changing environment of digital communications; but it is important to do so by looking at how the promises and imaginaries of a "networked feminism" and "digital sisterhood" translate into communicative practices of women's organisations, as they are situated within material conditions of limited funding and shaped by embodied experiences of ageing. 


\section{References}

Ahmed, S (2010) The promise of happiness. Duke University Press.

Atton, C (2002) Alternative media. London: SAGE.

Bennett, K (2009) No trafficking? Well, there's a hell of a lot of women suffering, The Observer [online] 25 October. Available at:

$<$ http://www.guardian.co.uk/commentisfree/2009/oct/25/catherine-bennett-prostitutiontrafficking $>$ [Accessed 17 July 2012].

Berry, D (2011) The philosophy of software. London: Palgrave Macmillan.

Braidotti, R (1996) Cyberfeminism with a difference. Electronic document at http://www.let.uu.nl/womens_studies/rosi/cyberfem.htm.

Bruns, A (2008). Blogs, Wikipedia, Second life, and Beyond: from production to produsage. New York, Peter Lang.

Chadwick, A (2006) Internet politics: States, citizens, and new communication technologies. Oxford University Press.

Chun, W H K (2011) Programmed visions: Software and memory. The MIT Press.

Couldry, N (2010) Why voice matters: Culture and politics after neoliberalism. Sage Publications.

Curran, J, Fenton, N, and Freedman, D (2012). Misunderstanding the Internet. London, Routledge.

Fernandez, M, Wilding, F and Wright , M (Eds.) Domain errors! Cyberfeminist practices (pp. 1728). New York: Autonomedia.

Fraser, N, and Honneth, A (2003) Redistribution or recognition?: a political-philosophical exchange. Verso.

Fuchs, C (2011) Foundations of critical media and information studies. Taylor \& Francis.

Gates, K (2011) Our biometric future: Facial recognition technology and the culture of surveillance. NYU Press.

Golumbia, D (2009) The cultural logic of computation. Harvard University Press.

Gupta, R (2009) Comment is Free: Sex trafficking is no illusion, The Guardian [online] 20 October, Available at: <http://www.guardian.co.uk/commentisfree/2009/oct/20/sex-trafficking-inquiry-nickdavies $>$ [Accessed 17 July 2012].

Haraway, D.J. (1991). Simians, cyborgs, and women: The reinvention of nature. London: Free Association Books.

Hayles, N K (2005). My mother was a computer: digital subjects and literary texts. Chicago, University of Chicago Press.

Helsper, E J (2008) Digital inclusion an analysis of social disadvantage and the information society. London, Department for Communities and Local Government.

http://www.communities.gov.uk/documents/communities/pdf/digitalinclusionanalysis

Hepp ,A (2008) Connectivity, networks and flows: conceptualising contemporary communications.

Cresskill, N.J., Hampton Press.

HOME OFFICE (2009) Violence Against Women and Girls strategy. Home Office. [online] Available at: $<$ http://www.homeoffice.gov.uk/crime/violence-against-women-girls/> [Accessed 25 November 2009].

Hooks, B (1986) "Sisterhood: Political solidarity between women." Feminist Review 23, pp. 125138.

Jolly, M, and Roseneil, S (2012) "Researching women's movements: An introduction to FEMCIT 
and Sisterhood and After." Women's Studies International Forum. Vol. 35. No. 3. Pergamon. Latour, B. \& Weibel, P (2005) Making things public: atmospheres of democracy, Cambridge, Mass.; [Karlsruhe, Germany], MIT Press; ZKM/Center for Art and Media in Karlsruhe.

Lovink, G (2002) Dark fiber: tracking critical internet culture, Cambridge, Mass., MIT Press.

Martin, A K, van Brakel, A. and Bernhard, D (2009) "Understanding resistance to digital surveillance: Towards a multi-disciplinary, multi-actor framework." Surveillance \& Society 6.3, pp.: 213-232.

Morgan, R (1970). Sisterhood is powerful. New York 1971.

North East Women's Network (2013), The Health of the Women's Sector in the North East of

England.

Paasonen, S (2011). Revisiting cyberfeminism. Communications. 36, 335-352.

Papacharissi, Z (2002) The virtual sphere: the internet as a public sphere. New Media \& Society, 4, 9-27.

Plant, S (1997) Zeros + ones: Digital women and the new technoculture. London: Fourth Estate.

Sollfrank, C and Old Boys Network (Eds.), First cyberfeminist international (pp. 60-64). Hamburg: OBN.

Portwood-Stacer, L (2012) "Anti-Consumption as Tactical Resistance: Anarchists, Subculture, and Activist Strategy." Journal of Consumer Culture 12, no. 1 (2012): 87-105.

Rosenfelt D and Stacey J (1987) 'Second Thoughts on the Second Wave' in Feminist Studies Vol. 13 No. 2 pp. 41-61

Schäfer, M (2010) Bastard culture! user participation and the extension of cultural industries.

Amsterdam, Amsterdam University Press.

subRosa, Fernandez, M, Wilding, F and Wright, M (2003). Introduction: Practicing cyberfeminisms. In M. Fernandez, F. Wilding \& M.M. Wright (Eds.), Domain errors! Cyberfeminist practices (pp. 9-13). New York: Autonomedia.

Taylor, C (2004). Modern social imaginaries. Durham, Duke University Press.

Townsend, M (2011) Sex-trafficked women's charity Poppy Project in danger as funding withdrawn, The Observer. [online] 17 April, Available at:

$<$ http://www.guardian.co.uk/society/2011/apr/17/prostitution-human-trafficking $>$ [Accessed 17 July 2012].

Van Dijck, J (2013) The Culture of Connectivity. Oxford: Oxford University Press.

VNS Matrix (1991). Cyberfeminist manifesto for the 21st century. Electronic document at http://www.obn.org/reading_room/manifestos/html/cyberfeminist.html.

WRC (2011) Assessing the Financial Vulnerability of Charities Serving Women, http://www.wrc.org.uk/includes/documents/cm_docs/2011/a/assessing_the_financial_vulnerabality_of_charities_servi ng_women.pdf 
The Fawcett Society was established in 1866.

ii $\quad$ 6.2 billion in cuts were announced in the 2010 emergency budget statement. These have affected women's organisations severely; over half of women's organisations have lost funding, year on year, since 2009; up to $40.6 \%$ in local authority spending on violence against women and girls' services (North East Women's Network, 2013).

iii Although feminist debates about misogyny, racism and feminism are an everyday occurrence in Twitter and the feminist blogsphere (see Loza, forthcoming), here my focus is less with individuals, and more on the motivations and implications of networked connectivity for community and volunteer sector organisations, with a wider gender equality agenda. See also fandom in relation to political, activism and Web 2.0 (Bury, 2005; Jenkins and Shresthova, 2012).

iv These were namely the regulation of lap dancing clubs, creating Brothel Closure Orders and creating a new criminal offence of paying for sexual services of a prostitute controlled for gain (Violence Against Women and Girls strategy, 2009, p.37).

$\checkmark$ The Commission has identified seven obstacles to what is understood as "a digital way of life" for European citizens (European Commission, 2010, p.5). These are: Fragmented digital markets, Lack of interoperability, Rising cybercrime and risk of low trust in networks, Lack of investment in networks, Insufficient research and innovation efforts, Lack of digital literacy and skills, Missed opportunities in addressing societal challenges.

vi It is estimated that there are currently 1,273 women's organisations in the UK (WRC, 2011).

vii All accounts have been anonymised.

viii Open architecture is the design principle of the internet, introduced by Robert Hahn and Vincent Cerf at DARPA, which denotes that individual and autonomous networks connect to the internet through common bridging protocols (for instance TCP/IP, URL, FTP, IRC) (Chadwick 2006). 